Bangladesh J. Bot. 38(2): 153-161, 2009 (December)

\title{
GENETIC DIVERSITY AND RELATIONSHIPS IN JUTE (CORCHORUS SPP.) REVEALED BY SSR MARKERS
}

\author{
SaAimatul Huq, Md. Shahidul Islam ${ }^{1}$, Abu Ashfaqur Sajib ${ }^{2}$, Nadim Ashraf ${ }^{3}$, \\ Samiul Haque ${ }^{1}$ and Haseena KhaN* \\ Plant Molecular Biology Laboratory, Department of Biochemistry and Molecular Biology, \\ University of Dhaka, Dhaka-1000, Bangladesh
}

Key words: Jute, Genetic diversity, SSR, Genotypes, Polymorphism

\begin{abstract}
Characterization of sixteen jute genotypes, from Corchorus olitorius L. and Corchorus capsularis L. using jute specific SSR marker attained a high polymorphism value of $92.20 \%$. A total of 171 different alleles were amplified by 27 primer pairs with a mean of $6.33 \pm 2.04$ alleles per locus. The genetic diversity was also relatively high $(0.81 \pm 0.06)$. The Un-weighted Pair-group Method with Arithmetic averages (UPGMA) cluster analysis of the 16 jute genotypes produced a dendogram, which was in concordance with known information. The study reinforces the utility of SSR primers for providing useful and high levels of markers for individual plant genotypes even with a narrow genetic base.
\end{abstract}

\section{Introduction}

Information on the genetic diversity within and among closely related crop varieties is essential for crop improvement and to meet the diverse goals like producing cultivars with increased yield (Joshi and Dhawan 1986), wider adaptability, desirable quality, pest and disease resistance, etc. (Nevo et al. 1982).

Simple Sequence Repeats (SSRs), also known as microsatellites, have been proven as an excellent tool for cultivar identification, pedigree analysis and the evaluation of genetic distances among many plant species (Priolli et al. 2002). These have been reported to detect high level of polymorphism even amongst closely related plant germplasms (Hokanson et al. 1998). SSR markers found to be more variable within genomes of olive than other molecular marker types (Mace et al. 2006). SSRs have become a tool of choice for investigations of unique genetic identities or fingerprints, determination of genetic relatedness between accessions, and the assessment of genetic diversity contained within a collection due to their co-dominant inheritance and amenability to high throughput analysis (Hokanson et al. 1998).

Jute (Corchorus species, $2 \mathrm{n}=14$ ) is a natural bast fibre crop and has considerable commercial significance. It includes 40 species, distributed in warm regions of the world (Purseglove 1968). However, for commercial purposes, jute fibre is obtained mostly from two cultivated species, $C$. capsularis L. and C. olitorius L. Studies on genetic diversity and relatedness at its molecular level have been surprisingly scarce. Analysis on jute genetic diversity has been reported by Hossain et al. (2002) and Qi et al. (2003a) using RAPD; Basu et al. (2004) using SSR and Roy et al. (2006) using STMS, ISSR and RAPD markers. Hossain et al. (2003) characterized cold-tolerant and coldsensitive jute germplasms and Qi et al. (2003b) classified wild jute species using Inter Simple Sequence Repeat (ISSR) marker. Recently Akter et al. (2008) and Mir et al. (2008) reported the utility of studying genetic variability for different traits in jute genotypes using jute specific SSR markers.

*Corresponding author. E-mail: pmblab@gmail.com ${ }^{1}$ Bangladesh Jute Research Institute, Dhaka, Bangladesh. ${ }^{2}$ Department of Genetic Engineering and Biotechnology, University of Dhaka,Bangladesh. ${ }^{3}$ University of Nottingham, U.K. 
The present study was undertaken to determine the genetic diversity and genetic relationships using SSR markers among 16 elite jute genotypes collected from BJRI.

\section{Materials and Methods}

Plant materials: The gene bank of Bangladesh Jute Research Institute (BJRI) has one of the world's largest jute and allied fibre (JAF) germplasm collection of about 6000 accessions. Eleven popular jute varieties (four from C. olitorius and seven from C. capsularis) and 5 advanced lines (these will be released within couple of years as varieties for commercial cultivation) used in this study were selected for their superior fibre yield, quality and other characteristics, collected from the Physiology Department, Bangladesh Jute Research Institute (BJRI), Dhaka. Details of the genotypes along with their breeding pedigree and geographic origins are given in Table 1.

Table 1. Breeding pedigree, geographic origin and superior characteristics of the jute genotypes used in the study.

\begin{tabular}{|c|c|c|c|c|c|}
\hline Species & Genotypes & $\begin{array}{l}\text { Variety/ } \\
\text { advanced line }\end{array}$ & Pedigree & $\begin{array}{l}\text { Geographical } \\
\text { origin }\end{array}$ & Superior characteristics \\
\hline \multirow[t]{9}{*}{ C. olitorius } & $\mathrm{O}-4$ & Variety & $\begin{array}{l}\text { Pure line selection } \\
\text { from local land } \\
\text { race }\end{array}$ & Bangladesh & High yield and good fibre quality \\
\hline & O-9897 & Variety & O-5 X BZ-5 & $\begin{array}{l}\text { O-5 (Bangladesh) } \\
\text { and BZ-5 (Brazil) }\end{array}$ & High yield and good fibre quality \\
\hline & Acc-1805 & Adv.line & $\begin{array}{l}\text { Pure line selection } \\
\text { against cold stress }\end{array}$ & Egypt & Cold tolerant \\
\hline & OM-1 & Variety & Pure line selection & Bangladesh & High yield and good fibre quality \\
\hline & $\mathrm{O}-72$ & Variety & $\begin{array}{l}(\mathrm{O}-9897 \text { X O- } \\
\text { 2012) X O-9897 }\end{array}$ & Bangladesh & High yield and good fibre quality \\
\hline & SDLT $-1^{*}$ & Adv. line & Pure line selection & Bangladesh & $\begin{array}{l}\text { High yield and good fibre quality, } \\
\text { tolerant to short day and low } \\
\text { temperature }\end{array}$ \\
\hline & SDLT $-2^{*}$ & as above & as above & Bangladesh & as above \\
\hline & SDLT $-3^{*}$ & as above & as above & Bangladesh & as above \\
\hline & Line $7 / 95$ & as above & O-4 X Uganda red & $\begin{array}{l}\text { O-4 (Bangladesh) } \\
\text { and Uganda red } \\
\text { (Uganda) }\end{array}$ & $\begin{array}{l}\text { High yield and good fibre quality, } \\
\text { mite tolerant }\end{array}$ \\
\hline \multirow[t]{7}{*}{ C. capsularis } & D-154 & Variety & $\begin{array}{l}\text { Pure line selection } \\
\text { from local land } \\
\text { race }\end{array}$ & Bangladesh & High yield and good fibre quality \\
\hline & CVL-1 & Variety & as above & Bangladesh & High yield and good fibre quality \\
\hline & CVE-3 & Variety & Pure line selection & Thailand & High yield and good fibre quality \\
\hline & $\mathrm{CC}-45$ & Variety & Pure line selection & Egypt & $\begin{array}{l}\text { High yield and good fibre quality, } \\
\text { less phtosensitive }\end{array}$ \\
\hline & BJC-83 & Variety & $\begin{array}{l}\text { CVL-1 X } \\
\text { Fuleshwari }\end{array}$ & Bangladesh & $\begin{array}{l}\text { High yield and good fibre quality, } \\
\text { early maturation }\end{array}$ \\
\hline & BJC-7370 & Variety & D-154 X CC-45 & Bangladesh & High yield and good fibre quality \\
\hline & BJC-2142 & Variety & CC-45 X S-718 & Bangladesh & $\begin{array}{l}\text { High yield and good fibre quality, } \\
\text { fibre colour snow-white }\end{array}$ \\
\hline
\end{tabular}

*Although these three lines were selected for tolerance to short day and low temperature, these were different in phenotypes.

DNA extraction: $1 \mathrm{~g}$ of four-day old seedlings were ground in presence of liquid nitrogen. DNA was extracted from the ground sample using the CTAB following a protocol modified from Doyle and Doyle's method (1990). DNA quality and quantity were checked following agarose gel 
electrophoresis $(0.8 \%$ gel containing $0.5 \mu \mathrm{g} / \mathrm{ml}$ ethidium bromide) using known concentrations of uncut lambda DNA as standard. The final DNA concentration of each template stock was adjusted to $50 \mathrm{ng} / \mu \mathrm{l}$.

Designing of SSR primers: Twenty seven primer pairs (Table 2), each flanking specific jute SSR sequences were used. The primers were designed from a SSR specific genomic library (developed by Vizon Sci. Inc., Canada) generated from an elite Bangladeshi jute variety O-4 that belongs to the species C. olitorius. Primers were designed following standard rules: 20-25 nucleotides in length, $40-60 \%$ GC content, and non-complementary $3^{\prime}$ nucleotides. Annealing temperatures for the primers were between $55^{\circ} \mathrm{C}-65^{\circ} \mathrm{C}$.

Table 2. Repeat motifs and primer sequences of microsatellite loci.

\begin{tabular}{|c|c|c|c|}
\hline $\begin{array}{l}\text { Primer } \\
\text { name }\end{array}$ & Forward & Reverse & Repeat motif \\
\hline HK-1 & CTTTCTTGACCCAAACAATGCCA & GGATGATGAAAAACGAAGTGCCTA & (AG)17G3(AG)20 \\
\hline $\mathrm{HK}-2$ & GTTTATCCAАCCAАTACCAАCCA & TGCCTCGTTGCTGGACATTGCA & (CT)11(GT)14 \\
\hline HK-4 & CAAAAGTAGTGAAGAACATGAGCA & GCCAAATTCTGATATACGCCTGA & (GT)28 \\
\hline HK-5 & AGTGACTTATAGTCTAATTAGTGA & ACAGATAGGATGTTAACGGGA & (GT)24 \\
\hline HK-6 & CTATCTCCCATTGTACCTGCA & GGCAGATTGTGTGAGACTATCA & (GT) 10 \\
\hline HK-7 & AATGATTATGAACCATAGTGGTACA & TTATCACAAAGTAGCAGACTAACA & $(\mathrm{GA}) 25$ \\
\hline HK-9 & TTACATTATATAATGTCCAGCCA & AGTGGCTACTGGTTCCTACA & (TC)21(T)33 \\
\hline HK-10 & GAACATCAAGACTGAGTAAGACCTA & TTGAGGATTTTCATATGCATGCA & (TG) 16 \\
\hline HK-12 & CGCTCGCCTAAGTGAAGGCA & ATAAAATACAAGGGACACTTAGCA & (CA) 19 \\
\hline HK-13 & TTAGGAGTCATTTCTAACAAGAC & АATCCСТCCAGCTTTCTCGA & (GA) 28 \\
\hline HK-15 & GAGAGGAATGATGCTGAGATTCA & GACACCCTCCGCCTATCTCA & $(\mathrm{GA}) 15$ \\
\hline HK-16 & TGGAACCTGAGCATCTCTCCAGA & CTTTTTCTTGTTCAGGGACCTGA & (CT) 21 \\
\hline HK-17 & AGAGTTTGCAACAAGGTAGCCA & TGGCTACTTAAACTTAGTTGTGTGCA & (GT)21 \\
\hline HK-18 & GCTGTTGTCTCTCTATTGGTGA & TTCCACGCTCCTTGTTGCCA & $(\mathrm{AG}) 16$ \\
\hline HK-19 & TATGAAGGTGAACTACTTGTCACA & AGCTTCCATTTCGAACATTCCA & $(\mathrm{CA}) 21(\mathrm{AG}) 10$ \\
\hline HK-20 & GTAAAGCACAGGATTAGTCCCA & GGAAAGTGAACCTCTAGTAGATGA & (CT)30 \\
\hline HK-21 & AATCAAATTGAGAATGGACATGCA & GAAAGGCAAATGCGCTTGTTGA & (CA) 12 \\
\hline HK-22 & CTGTTTGTCAATCTCTTTTGAGTCA & GTCCAAAACATCGTGCAGTGTGA & $(\mathrm{GA}) 25$ \\
\hline HK-23 & GGCCCTTCTAATTAACCTCCA & AGTTTTGTTTCCAGATATTGCTCA & (GA) 17 \\
\hline HK-27 & TTGTGTGCAAACACGAGTGCA & GGTAGCCATGTTTACTTCCTGA & (CA)26 \\
\hline HK-28 & AGAGACGAGTAAACATAAAAGTCC & CTGGCGAAGCCTTAAAAATGCA & $(\mathrm{AG}) 21$ \\
\hline HK-29 & CTGAATGAAAGATTGCTTTTAATCC & CATGCATCATTTGCATTGCATGCA & $(\mathrm{GA}) 39$ \\
\hline HK-30 & GAGTGATTAGAGGGCAGCCA & TGCAACAAAGTATCCAAATCGAC & $(\mathrm{CA}) 21$ \\
\hline HK-33 & GTTGATATCTTTACGGTGTATAGA & GTGATTTTGGTTACTATGACCCA & $(\mathrm{CA}) 16(\mathrm{TA}) 6$ \\
\hline HK-37 & AATGTGAAATCCAATTAAAGCACA & CCAAGATTGTAGCAACAAGCCA & (GATA) 13 \\
\hline HK-38 & ACCAAGTATGATCTGACCTCT & $\begin{array}{l}\text { AGCTAAAAACAACACAAAAATATCT } \\
\text { TGC }\end{array}$ & $(\mathrm{CTAT}) 16$ \\
\hline HK-41 & GGAAAACAGCCTATTGGGGACA & CATTCCTCCATTGTTGAAGGA & $(\mathrm{CAA}) 15$ \\
\hline
\end{tabular}

PCR amplification: PCR was performed in GeneAmp ${ }^{\circledR}$ PCR system 9700 (Applied Biosystems). Each of the $25 \mu 1$ reaction mixtures contained $50 \mathrm{ng}$ of jute genomic DNA, $10 \mu \mathrm{M}$ of each primer pair, $1 \times$ PCR buffer, $2.5 \mathrm{mM} \mathrm{MgCl} 2,2 \mathrm{mM}$ dNTPs, 1 unit Taq DNA polymerase (Invitrogen, India). The thermal cycler was programmed as follows: preheating for $5 \mathrm{~min}$ at $95^{\circ} \mathrm{C}$; 35 cycles, each for $30 \mathrm{~s}$ at $95^{\circ} \mathrm{C}$ (denaturation), $40 \mathrm{~s}$ at the annealing temperature of a particular primer pair, and $30 \mathrm{~s}$ at $72^{\circ} \mathrm{C}$ (extension) and a final extension at $72^{\circ} \mathrm{C}$ for $5 \mathrm{~min}$, followed by cooling at $4^{\circ} \mathrm{C}$ for infinite period.

Separation and staining of PCR products: Before loading in gels, PCR products were denatured by adding equal volume of tracking dye ( $95 \%$ formamide, $10 \mathrm{mM}$ EDTA, $0.23 \%$ 
bromophenol blue and $0.23 \%$ xylene cyanol) and heating at $94^{\circ} \mathrm{C}$ for $5 \mathrm{~min}$. Amplified products were separated in $8 \%$ denaturing polyacrylamide gel in $1 \times$ TBE buffer adjusted to $\mathrm{pH} 8.3$ at 2000 $\mathrm{V}$ for 2.5-3 h, using sequencing gel apparatus (Adjustable nucleic acid sequencing unit, Model SG-400-33, C.B.S. Scientific Co. Del Mar, California). Silver staining of the gels was performed according to Streiff et al. (1998). Fragment sizes were calculated using the computer programme SEQAID II (Fragment Sizer) by comparing with fragments of 1kb-plus ladder marker DNA (Invitrogen, India).

Data analysis: Amplified PCR products were scored to create a binary matrix. Effective allele per locus $\left(\mathrm{A}_{\mathrm{ep}}\right)$ were calculated according to Weir (1990) using formula $1 /\left(1-\mathrm{H}_{\mathrm{ep}}\right)$, where $\mathrm{H}_{\mathrm{ep}}$ (the genetic diversity per locus) is equal to $1-\Sigma \mathrm{P}_{\mathrm{i}}^{2}$ and $\mathrm{P}_{\mathrm{i}}$ is equal to the frequency of the $\mathrm{i}^{\text {th }}$ allele of this locus.

Shannon's diversity index was calculated according to Martynov et al. (2003) with the formula $\mathrm{H}=-\sum \mathrm{P}_{\mathrm{i}} \ln \left(\mathrm{P}_{\mathrm{i}}\right)$, where $\mathrm{P}_{\mathrm{i}}$ is the frequency of a particular allele $i$ and $\ln$ is the symbol of natural logarithm. A pair-wise distance matrix was generated based on total and mean character differences in phylogenetic analysis (Swofford 2002). A dendrogram was constructed to identify genetic relatedness among the cultivars based on the distance matrix by applying the Un-weighted Pair-group Method with Arithmetic averages (UPGMA) cluster analysis using the software STATISTICA.

\section{Results and Discussion}

Studies on 16 elite jute genotypes, twenty seven SSR primer pairs yielded a total of 171 different alleles with an average of $6.33 \pm 2.04$ alleles per locus (Table 3), which differed from $4.61 \pm 1.92$ and 3.04 found by Akter et al. (2008) and Mir et al. (2008), respectively. Differences in average number of alleles might arise from using different combination of genotypes and different loci in present study. Only reproducible and distinct bands were counted in the analysis. Though SSRs are generally believed to be locus specific and expected to amplify single or twin bands with a single SSR primer, we observed multiple alleles. Similar results were obtained by Gupta et al. (2003). This might arise from amplification of more than homeolocus as was explained by Holton et al. (2002). The observed allele sizes ranged from $110 \mathrm{bps}$ (HK-30) to 480 bps (HK-28). Di-nucleotide repeats had more alleles (average 6.5) compared to tri and tetranucleotide repeats (average 5). 158 of the total 171 alleles amplified were polymorphic giving an average $5.85 \pm 2.12$ polymorphic alleles per locus (Table 2). Although jute is self-pollinating and incompatible for inter-specific cross hybridization which results in a narrow genetic base, this study attained a high polymorphism of $92.20 \%$ with SSRs which was similar to Akter et al. 2008 (92.45\%) and Mir et al. 2008 (91.11\%). Similar levels of polymorphisms for SSRs were also reported in previous studies with other plant species (Rajora and Rahman 2003). This study, therefore, reinforces the utility of SSR primers for providing useful and high levels of markers for individual plant genotypes even with a narrow polymorphic genetic background. The present study differs significantly from Mir et al. (2008) in using varieties that are widely used in Bangladesh, and from Akther et al. (2008) in having more genotypes including five advanced lines, which are on the verge of commercial release soon. In addition, this study involves loci, different from previous studies. The more markers are available for a species the more helpful it might be in future for various analysis such as gene identification, MAS, etc.

The minimum and maximum numbers of alleles obtained at different loci were 3 and 10, respectively (Table 3 ). The effective number of alleles per locus was smaller than the observed numbers of alleles in the corresponding locus except for locus HK-21 and HK-41. A similar pattern was observed in other plants such as orchid (Gustafsson 2000), neotropical tree Swietenia humilis Zucc (White et al. 1999) and grapes (Martínez et al. 2006). However, the differences 
between the observed number of alleles and expected number of alleles were more pronounced in these plants than jute. Genetic diversity (GD), which is indicative of the effectiveness of SSR loci information, was relatively high, ranging from 0.66 (HK-13) to 0.89 (HK-4), with a mean value of $0.81 \pm 0.06$, which was slightly higher than Akter et al. (2008). This discrepancy may have arisen due to the inclusion of more genotypes and loci in the present study. Another reason for this could

Table 3. Range of allele size, number of allele, number of effective allele, genetic diversity $( \pm \mathrm{SE})$ and polymorphism at 27 SSR loci (defined by primer pair) in sixteen jute genotypes

\begin{tabular}{|c|c|c|c|c|c|c|}
\hline Locus & $\begin{array}{l}\text { Range of } \\
\text { allele size } \\
\text { (bp) }\end{array}$ & $\begin{array}{l}\text { Number of } \\
\text { allele } \\
\text { (A) }\end{array}$ & $\begin{array}{c}\text { Number of } \\
\text { effective allele } \\
\left(A_{\text {ep }}\right)\end{array}$ & $\begin{array}{l}\text { Genetic } \\
\text { diversity } \\
\text { (GD) }\end{array}$ & $\begin{array}{l}\text { Polymorphi } \\
\text { c band } \\
(\%)\end{array}$ & $\begin{array}{l}\text { Shannon's } \\
\text { diversity index } \\
\text { (I) }\end{array}$ \\
\hline HK-1 & $150-300$ & 6 & 5.29 & 0.81 & 83.33 & 1.73 \\
\hline HK-2 & $140-290$ & 7 & 6.03 & 0.83 & 100.00 & 1.86 \\
\hline HK-4 & $130-390$ & 10 & 9.50 & 0.89 & 100.00 & 2.28 \\
\hline HK-5 & $110-280$ & 6 & 5.16 & 0.81 & 83.33 & 1.71 \\
\hline HK-6 & $130-370$ & 9 & 7.54 & 0.87 & 88.89 & 2.10 \\
\hline HK-7 & $230-310$ & 4 & 3.95 & 0.75 & 100.00 & 1.38 \\
\hline HK-9 & $160-400$ & 6 & 4.92 & 0.80 & 83.33 & 1.70 \\
\hline HK-10 & $150-430$ & 8 & 6.12 & 0.84 & 100.00 & 1.93 \\
\hline HK-12 & $100-390$ & 9 & 8.36 & 0.88 & 100.00 & 2.15 \\
\hline HK-13 & $340-390$ & 3 & 2.96 & 0.66 & 100.00 & 1.09 \\
\hline HK-15 & $140-280$ & 7 & 6.40 & 0.84 & 71.43 & 1.90 \\
\hline HK-16 & $150-320$ & 5 & 4.63 & 0.78 & 60.00 & 1.57 \\
\hline HK-17 & $200-400$ & 4 & 3.74 & 0.73 & 75.00 & 1.35 \\
\hline HK-18 & $110-400$ & 8 & 6.44 & 0.84 & 100.00 & 1.94 \\
\hline HK-19 & $120-190$ & 7 & 6.28 & 0.84 & 85.71 & 1.88 \\
\hline HK-20 & $110-260$ & 9 & 8.61 & 0.88 & 100.00 & 2.18 \\
\hline HK-21 & $170-240$ & 3 & 3.00 & 0.67 & 100.00 & 1.10 \\
\hline HK-22 & $220-350$ & 6 & 5.47 & 0.82 & 100.00 & 1.73 \\
\hline HK-23 & $130-310$ & 8 & 7.31 & 0.86 & 75.00 & 2.03 \\
\hline HK-27 & $180-360$ & 6 & 5.22 & 0.81 & 83.33 & 1.72 \\
\hline HK-28 & $280-480$ & 5 & 4.43 & 0.77 & 100.00 & 1.54 \\
\hline HK-29 & $210-380$ & 6 & 5.03 & 0.80 & 100.00 & 1.67 \\
\hline HK-30 & $100-210$ & 10 & 7.89 & 0.87 & 100.00 & 2.17 \\
\hline HK-33 & $200-400$ & 4 & 3.37 & 0.70 & 100.00 & 1.28 \\
\hline HK-37 & $140-390$ & 4 & 3.72 & 0.73 & 100.00 & 1.34 \\
\hline HK-38 & $100-400$ & 6 & 5.54 & 0.82 & 100.00 & 1.74 \\
\hline HK-41 & $110-310$ & 5 & 5.00 & 0.80 & 100.00 & 1.61 \\
\hline Mean & & $6.33 \pm 2.04$ & $5.62 \pm 1.74$ & $0.81 \pm 0.06$ & 92.20 & $1.73 \pm 0.32$ \\
\hline
\end{tabular}

be the inclusion of more genotypes from C. olitorius which have higher genetic diversity than those of C. capsularis. This has also been observed by Akter et al. (2008) and Mir et al. (2008). This high GD value indicates that SSRs were highly informative for jute. Genetic diversity and number of alleles were positively correlated (Fig. 1). GD values increased proportionally with increasing heterozygosity at any locus. The frequency of $84 \%$ of the 171 detected alleles was 
lower than 0.25 , and that of the remaining $16 \%$ was equal to or higher than 0.25 . Only three alleles amplified with primer pairs HK-6, HK-12 and HK-29 showed a frequency lower than 0.05 (Data not shown).

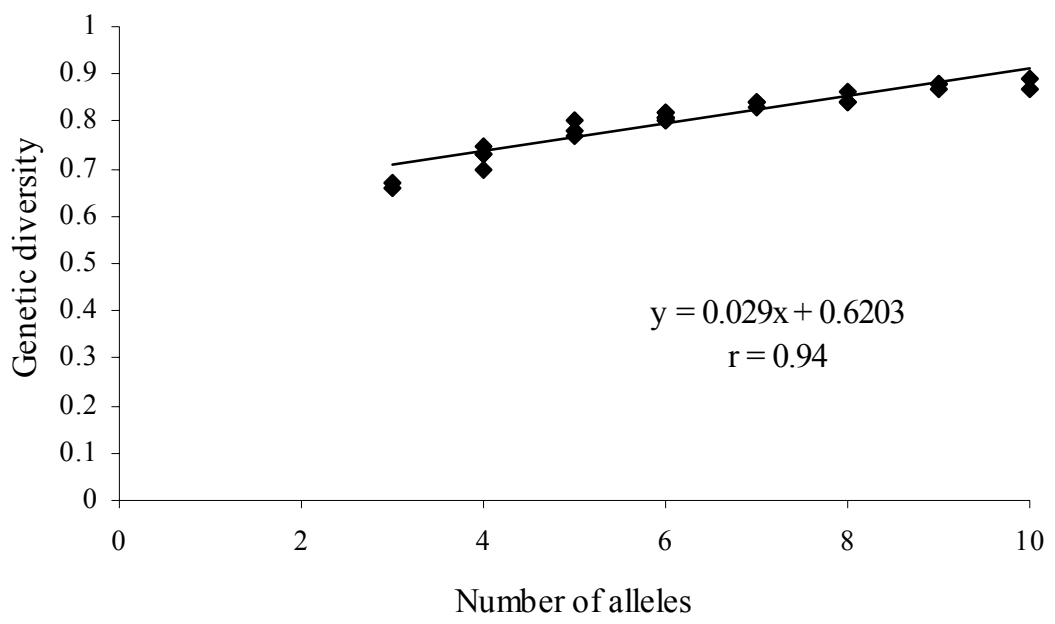

Fig. 1. Relationship between number of alleles at individual locus and genetic diversity among jute genotypes.

Two frequently used statistical tools for genetic diversity studies are percentage of polymorphic bands (P) and Shannon's diversity index (I). In this study, 17 out of 27 loci had $100 \%$ polymorphic alleles (Table 3 ) with HK-16 locus having the least polymorphism $(60 \%)$. Shannon's diversity index (I) of the jute cultivars ranged between 1.09 (HK-13) and 2.28 (HK-4) with an average of $1.73 \pm 0.32$ (Table 3 ) and was directly proportional to the number of polymorphic alleles at corresponding loci.

The UPGMA cluster analysis produced two meaningful groups with genotypes belonging to Corchorus olitorius and C. capsularis in two different major clusters I and II (Fig. 2). The first group (cluster I) included all the genotypes from C. olitorious and the second group (cluster II) included all the genotypes from C. capsularis. This pattern of clustering validates the authenticity of the experiment and reliability of data, which was in concordance with available taxonomical information and previous studies by Hossain et al. (2002) using RAPD, Basu et al. (2004) using AFLP, Roy et al. (2006) using STMS, ISSR and RAPD markers, Akther et al. and Mir et al. (2008) using jute specific SSR markers. Both the clusters were further subdivided into three subclusters. Sub-cluster Ia comprised three genotypes namely, O-4, O-9897 and accession 1805, Subcluster Ib comprised four genotypes namely, OM-1, O-72, SDLT-1, and SDLT-2 and Subcluster Ic comprised two genotypes namely, SDLT-3 and Line 7/95. Sub-cluster IIa comprised two genotypes namely, D-154 and CVL-1, Sub-cluster IIb comprised three genotypes namely, CVE-3, CC-45 and BJC-83 and Sub-cluster IIc comprised two genotypes namely, BJC-7370 and BJC2142. The present study revealed that the two jute species are distantly related. Palit et al. (1996) also reported presence of distinct patterns of diversity between the two species. This analysis, thus, strengthened the earlier concept that the two species originated from two different geographical locations; C. capsularis originated from the Indo-Burma region and C. olitorius from Africa (Kundu 1951). 


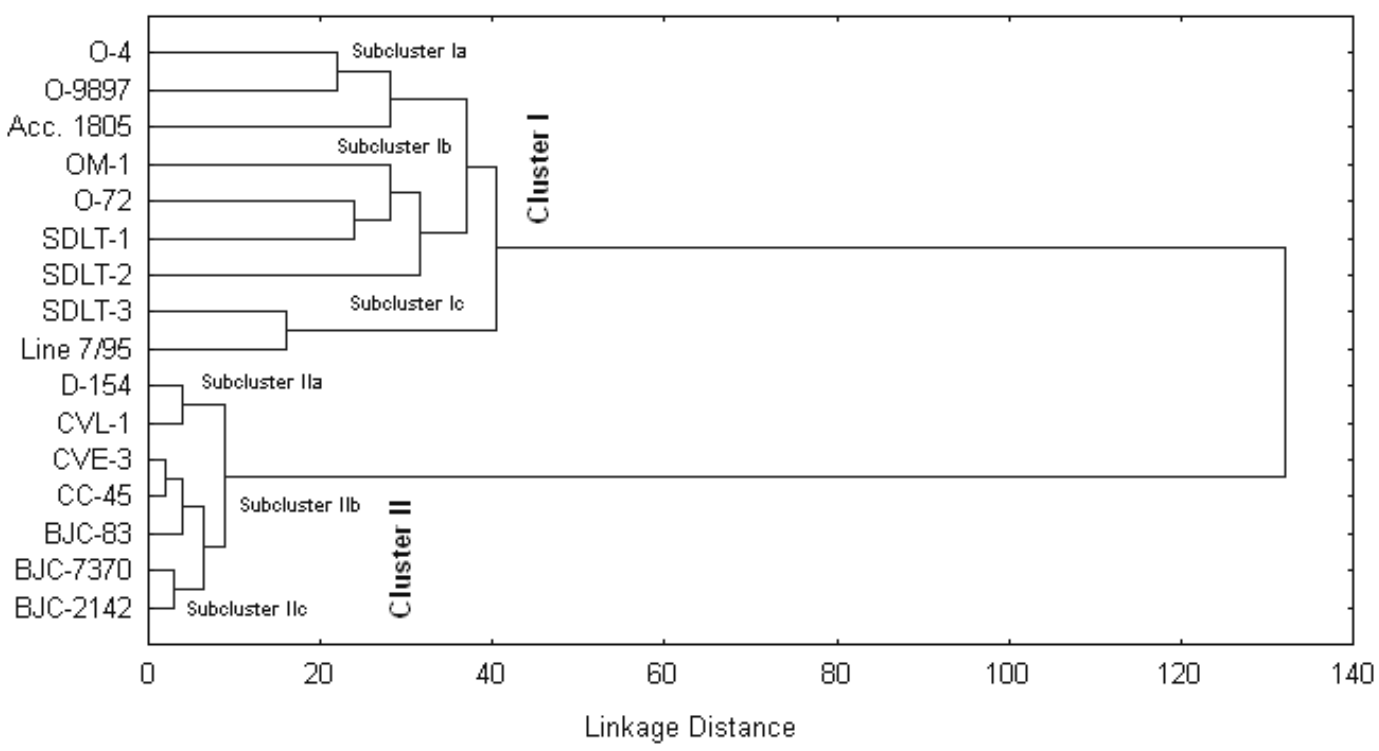

Fig. 2. Dendrogram of 16 jute genotypes based on data on allelic profiles generated using 27 microsatellite primer pairs.

The average genetic distance among the C. olitorius cultivars was 35.5 units and C. capsularis cultivars was 6.86 units and distance between the species was 138.17 units indicating the low level of diversity in C. capsularis than C. olitorius. Similar conclusion was drawn in analysis by Akter et al (2008) and Mir et al. (2008). This might be correlated to the lower percentage (3-4\%) of out-crossing in C. capsularis as opposed to relatively higher percentage $(8-12 \%)$ of natural cross pollination within C. olitorius (Ghose and Gupta 1945). Roy et al. (2006) also observed low levels of diversity in the C. capsularis varieties.

These SSR markers showed great promise as tools for collection and preservation strategies concerning various jute cultivars in situ. The ease of detection and the success of this study with SSR markers to elucidate the diversity among 16 cultivars may encourage the use of SSR markers to characterize all the germplasms (nearly 6000) at BJRI. This will surely reduce duplication in the collection, if any, and will be more useful to the user community. The information on genetic relatedness and characterization of cultivars will also help in making informed choices on selection of parental material based on genetic diversity. In addition, these SSR markers may be positioned on genetic maps, which may further facilitate plant breeders and geneticists to localize agronomically/horticulturally significant genes or gene complexes to specific sites on the genome (Liu et al. 1996). These traits could be introduced into desired cultivars by marker-assisted selection or map-based cloning.

\section{Acknowledgements}

Authors gratefully acknowledge Dr. Selina Begum, Chief Scientific Officer, Bangladesh Jute Research Institute, Dhaka for supplying the jute seeds. Authors are also grateful to the U.S. Department of Agriculture (USDA) for the financial support. 


\section{References}

Akter J., M.S. Islam, A.A. Sajib, N. Ashraf, S. Haque and H. Khan. 2008. Microsatellite markers for determining genetic identities and genetic diversity among jute cultivars. Australian J. Crop Sci. 1(3): 97-107.

Basu A, M. Ghosh, R. Meyer, W. Powell, S.L. Basak and S.K. Sen. 2004. Analysis of genetic diversity in cultivated jute determined by means of SSR markers and AFLP profiling. Crop Sci. 44: 678-685.

Doyle J.J. and J.L. Doyle. 1990. Isolation of plant DNA from fresh tissue. Focus 12: 13-15.

Ghose R.L.M. and B.D. Gupta. 1945. Floral biology, anthesis and natural crossing in jute. Indian J. Genet. 4: 80-84.

Gustafsson S. 2000. Patterns of genetic variation in Gymnadenia conopse, the fragrant Orchid. Mol. Ecol. 9: $1863-1872$

Gupta P.K., S. Rustgi, S. Sharma, R. Singh, N. Kumar and H.S. Balyan. 2003. Transferable EST-SSR markers for the study of polymorphism and genetic diversity in bread wheat. Mol. Gen. Genomics 270: $315-323$.

Hokanson S.C., A.K. Szewc-McFadden, W.F. Lamboy and J.R. McFerson. 1998. Microsatellite (SSR) markers reveal genetic identities, genetic diversity and relationships in Malus $\times$ domestica borkh. Core subset collection. Theor. Appl. Genet. 97: 671-683.

Holton T.A., J.T. Christopher, L. McClure, N. Harker and R.J. Henry. 2002. Identification and mapping of polymorphic SSR markers from expressed gene sequences of barley and wheat. Mol. Breed. 9: 63-71.

Hossain M.B., S. Haque and H. Khan. 2002. DNA Fingerprinting of jute germplasm by RAPD. J. Biochem. Mol. Biol. 35(4): 414-419.

Hossain M.B., A. Awal, M.A. Rahman, S. Haque and H. Khan. 2003. Distinction between cold-sensitive and -tolerant jute by DNA polymorphisms. J. Biochem. Mol. Biol. 35(5): 427-432.

Joshi A.B. and N.L. Dhawan. 1986. Genetic improvement of yield with special reference to self fertilizing crops. Indian J. Genet. 26(1): 101-113.

Kundu B.C. 1951. Origin of jute. Indian J. Genet. Plant Breed. 11: 95-99.

Liu Z.W., R.M. Biyashev and M.A.S. Maroof. 1996. Development of simple sequence repeat DNA markers and their integration into a barley linkage map. Theor. Appl. Genet. 93: 869-876.

Mace E.S., W. Yuejin, L. Boshou, H. Upadhyaya, H. Chandra and J.H. Crouch. 2006. Simple sequence repeat (SSR)-based diversity analysis of groundnut (Arachis hypogaea L.) germplasm resistant to bacterial wilt. Plant Genetic Resources 5(1): 27-36.

Martínez L.E., P.F. Cavagnaro, R.W. Masuelli and M. Zúñiga. 2006. SSR-based assessment of genetic diversity in South american Vitis vinifera varieties. Plant Sci. 170: 1036-1044.

Martynov S.P., T.V. Dobrotvorskaya, L. Dotlacil, Z. Stehno, I. Faberova and I. Bares. 2003. Genealogical approach to the formation of the winter wheat core collection. Russian J. Genet. 39(8): 917-923.

Mir R.R., S. Rustgi, S. Sharma, R. Singh, A. Goyal, J. Kumar, A. Gaur, A.K. Tyagi, H. Khan, M.K. Sinha, H.S. Balyan and P.K. Gupta. 2008. A preliminary genetic analysis of fibre traits and the use of new genomic SSRs for genetic diversity in jute. Euphytica 161: 413-427.

Nevo E., E. Golenberg, A. Beilies, A.H.D. Brown and D. Zohary. 1982. Genetic diversity and environmental association of wild wheat, Triticum diococcoides in Israel. Theor. Appl. Genet. 62: 241-254.

Palit P., B.C. Sasmal and A.C. Bhattacharryya. 1996. Germplasm diversity and estimate of genetic advance of four morpho-physiological traits in a world collection of jute. Euphytica 90: 49-58.

Purseglove J.W. 1968. Tropical Crops. Dicotyledons 2: 613-618. Longhman, London. 719 pp.

Priolli R.H.G., C.T. Mendes-Junior, N.E. Arantes and E.P.B. Contel. 2002. Characterization of Brazilian soybean cultivars using microsatellite markers. Genet. Mol. Biol. 25(2): 185-193

Qi J., D. Zhou, W. Wu, L. Lin, P. Fang and J. Wu. 2003a. The application of RAPD technology in genetic diversity detection of Jute. Ying Yong Sheng Tai Xue Bao 30: 926-932.

Qi J., D. Zhou, W. Wu, L. Lin, J. Wu and P. Fang. 2003b. Application of ISSR technology in genetic diversity detection of jute. Ying Yong Sheng Tai Xue Bao 14: 1473-1477. 
Rajora O.P. and M.H. Rahman. 2003. Microsatellite DNA and RAPD fingerprinting, identification and genetic relationships of hybrid poplar (Populus $\times$ canadensis) cultivars. Theor. Appl. Genet. 106: 470-477.

Roy A., A. Bandyopadhyay, A.K. Mahapatra, S.K. Ghosh, N.K. Singh, K.C. Bansal, K.R. Koundal and T. Mohapatra. 2006. Evaluation of genetic diversity in jute (Corchorus species) using STMS, ISSR and RAPD markers. Plant Breed. 125: 292-297.

Streiff R., T. Labbe, R. Bacilieri, H. Steinkellner, J. Glosslè and A. Kremer. 1998. Within-population genetic structure in Quercus robur L. and Quercus petraea (Matt.) Liebl. assessed with isozymes and microsatellites. Mol. Ecol. 7:317-328.

Swofford D.L. 2002. PAUP*. Phylogenetic Analysis Using Parsimony (*and Other Methods). Version 4. Sinauer Associates, Sunderland.

Weir B.S. 1990. Genetic data analysis methods for discrete population genetic data. Sinauer Associates, Sunderland. $445 \mathrm{pp}$.

White G.M., D.H. Boshier and W. Powell. 1999. Genetic variation within a augmented population of Swietenia humilis Zucc. Mol. Ecol. 8: 1899-1909.

(Manuscript received on 7 January, 2009; revised on 15 September, 2009) 